France, the Observatory in its republican eclipse, war production and an exhibition of French industry, governmental science policy and administration, the nascent metric system itself-these are the chief sights in this tour of the most highly institutionalized scene that science had yet developed, where it was first wearing its modern dress of a professional enterprise that really mattered to the state.

Charles C. Gillispie

\section{INTRODUCTION TO SOCIOLOGY}

\section{Introducing Sociology}

By Peter Worsley, Roy Fitzhenry, J. Clyde Mitchell, D. H. J. Morgan, Valdo Pons, Bryan Roberts, W. W. Sharrock and Robin Ward. Pp. 416. (Penguin: Harmondsworth, Middlesex, 1970.) $15 s$.

ACADEMIC sociology has been a long time growing up. It was a relatively minor discipline until quite recently; minor in terms of the numbers of teachers and taught, and probably minor in terms of academic achievement. Its acadomic pretensions were huge, for it was planned by some practitioners to be no less than the general science of society of which other disciplines, like economics and psychology, were but small particular parts. At the end of the 1950s and in the carly 1960s, with the rapid expansion of higher education that then occurred, sociology became an extremely popular subject, and it is now not only a large subject in its own right among honours graduates and research students but it is also an important "minor option" in many courses, particularly in science and technology. Because it is rarely taught at school, tho need for good mature introductory books is obvious.

There is a problem about introductory textbooks in the social sciences, because normally a student who takes up what is, after all, predominantly a literary study could be expocted to read a considerable number of books, and five or six books in a woek or two will almost always give a better idea of what sociology is about than a painstaking introductory text gone through paragraph by paragraph, as presumably introductory texts to a natural science would be. Thus, the problem of introducing this subject to intelligent students of 18-plus for the first time is accentuated by a problem of methodology.

It is fair to say that Professor Worsley's collection is much better than most. It attempts to present recent research to the students as part of a process of introducing elementary sociological concepts to them, and in this way to catch their interest and to explain exactly what it is that sociologists are up to. In particular the chapter on sociological method is a model of its kind. Two drawbacks, however, remain. The first is that which is common to almost all introductory texts of sociology, an enormous. ponderous and tedious chapter on what sociology is about, in which some of the more absurd and grandiose claims still remain, though in attenuated forms. The second is a considerable weakness on the mathematical side. In so far as social sciences have academic standing, one part of their claim to intellectual achievement; rests on the application of mathematical techniques to problems of the social order. This mathematical approach is virtually absent from this book. So, ton, is any serious discussion of ideas as such. A French student, for example, would, I think, find this a particularly unintellectual book. Have the students perhaps been talked down to ? Seeking to avoid boredom, the writers may have achieved light weight, not light heartedness.

The strongest chapter is on the family; the weakest is on education, where, disappointingly, the impression gained from a careful reading of the chapter is of a series of dispirited slogans rather than of any attempt at rigorous analysis.

\section{LAB BEHAVIOUR}

The Social Behaviour of Animals

By Stuart J. Dimond. Pp. 256. (Batsford: London, August 1970.) 50s.

THE upsurge of interest in recent years in the social behaviour of animals has been largely based on compara. tive field studies of various primate species. Whether openly admitted or not the hope has been to find something of the beginnings of human society. Dr Dimond offers a review of tho possibilities which lie in an analytical laboratory approach--tho psychologist's rather than the ethologist's. 'This puts more weight on the acquisition of the elements of social behaviour through early experience, and later by social motivation. Parental and sexual bchaviour, aggression, status relationships and group behaviour can all be subjects for operant techniques, thus a female monkey will, for instance, press a lever which opens a window through which she can see her own infant. 'The strength of lever pressing gives a measure of the strength of the urge to be rewarded in this way. Cooperation between animals in obtaining rewards was first tested by Skinner; new work shows that if a rat pressing a lever for food gives a shock to another rat, the first rat's rate of pressing will go down if it can see its effect on the second one. These are all ways of moasuring relationships, though one would sometimes be happier if a parallel to behaviour in the wild was more obvious.

Evidence of the operant conditioning of tho autonomic system suggests to Dimond that this may bo a cause of social responses. For the autonomic changes bring about changes in endogenous processes, for oxamplo, hormone production, which in their turn cause the social responses. A theory which could explain some of the effects of early experience.

All too briefly Dimond criticizes over-facile generalization from animals to man. The strength of his critique would be groater if he took more examples from the workers ho takes to task.

Perhaps brevity is a fault of this book for the discussions are short and the evidence is not abundant: nevertheless, it is a useful introduction to this approach to social behaviour.

J. D. Carthy

\section{MODELS OF THE MIND}

The Computer Simulation of Behaviour

By Michael J. Apter. Pp. 180. (Hutchinson: London, August 1970.) $35 s$ boards; $15 s$ paper.

THIs book is intended "to examine how far one can accept the mechanist hypothesis in psychology" and "to evaluate the usefulness of computer simulation as a technique to be used by psychologists". By "mechanist hypothesis in psychology" the author has in mind the hypothesis that a machine could exhibit consciousness or self-awareness. In the final chapter on "Consciousness", an attempt is made to discuss this issue. The most significant feature of this attempt is the almost complete failure to utilize evidence or ideas drawn from the material of the preceding 150 pages on computer simulation. Fven the most primitive model - that mind is to brain as program is to computer-passes unmentioned in spite of the obvious connexion it provides between the question and tho study of complex computing systems. Chomsky. who, togother with colleagues such as J. J. Katz, has contributed immonsely to a clearer understanding of mentalism, gets no mention under this heading save for an earlier footnote (p. 138) where the reader is warned "that Chornsky's theorizing is sometimes, especially where he uses the concept 'mind', far from rigorous"!

As to the author's second objective, again there is a singular failure to juxtapose the realities of current methodologies in experimental psychology, for example, 